\title{
3.7 Інформаційно-розрахункова система підтримки прийняття рішення "Аргумент - 2021"
}

Інформаційно-розрахункова система “Аргумент-2021” призначена для підтримки прийняття рішення командиром частини ЗРВ при виборі бойового порядку частин та підрозділів ЗРВ і оцінки ефективності бойових дій угруповання ЗРВ яке створено.

Програмне забезпечення інформаційно-розрахункової системи забезпечує: відображення тактичної обстановки угруповання ЗРВ та військ що прокриваються на цифрової карті; розрахунок кутів закриття і побудова профілів місцевості; розрахунок зони радіолокаційної видимості радіоелектронних засобів з урахуванням рельєфу місцевості; розрахунок зон поразки ЗРК (вогню) на заданих користувачем висотах дій повітряного противника; розрахунок кратності перекриття реалізованих зон поразки; розрахунок кількості стрільб ЗРК до рубежів виконання бойових завдань; розрахунок маневрених можливостей частин і підрозділів ЗРВ; оцінка ефективності бойових дій частин та підрозділів ЗРВ.

До вхідної інформації (дані для ініціалізації програми) відноситься наступна: район на карті в якому розміщуються угруповання ППО та параметри відображення карти; цифрова модель місцевості; бойовій склад, озброєння частин та підрозділів ППО; бойовій порядок угруповання ППО; тактико технічні характеристики озброєння ППО; бойовій склад, озброєння частин та підрозділів противника; параметрі нальотів засобів повітряного нападу.

Структура інформаційно-розрахункової системи "АРГУМЕНТ 2021" наведена на рис. 1. 


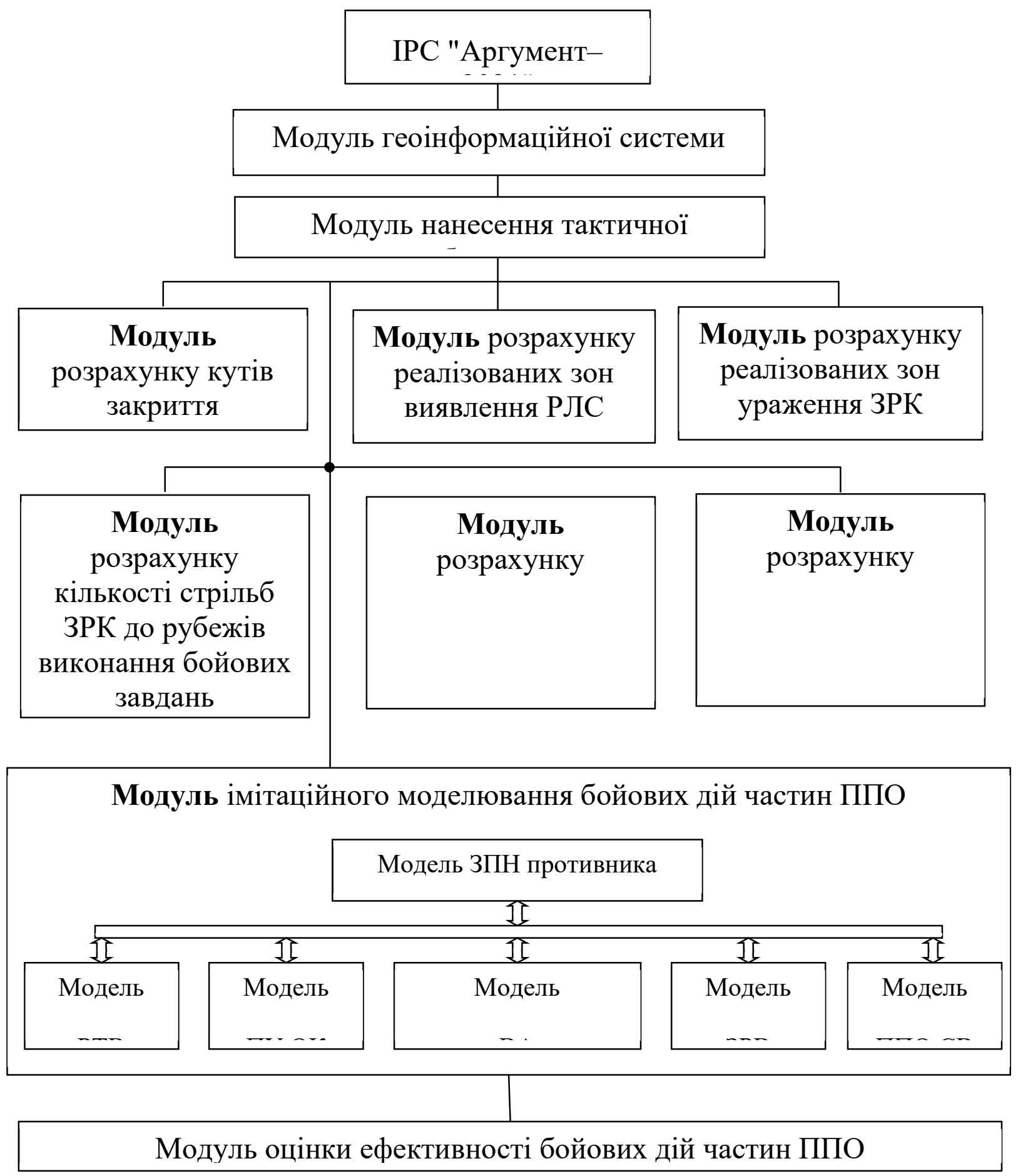

Рис. 1 Структура інформаційно-розрахункової системи

Вихідною інформацією інформаційно-розрахункової системи є: відображення тактичної обстановки угруповання ЗРВ та військ що прокриваються на цифрової карті; розрахунок кутів закриття і побудова профілів місцевості; графічне зображення реалізованих зон виявлення РЛС з урахуванням рельєфу місцевості; графічне зображення реалізованих зон ураження ЗРК РЛС 3 
урахуванням рельєфу місцевості; розрахунок кратності перекриття реалізованих зон поразки; розрахунок кількості стрільб ЗРК до рубежів виконання бойових завдань; результати моделювання бойових дій угруповання ППО у вигляді таблиць; оцінка ефективності бойових дій частин та підрозділів ППО.

В програмних модулях системи використовується наступний математичний апарат [240]: алгоритм розрахунку кутів закриття; алгоритм розрахунку реалізованих зон виявлення РЛС, з урахуванням рельєфу місцевості; алгоритм розрахунку реалізованих зон ураження ЗРК, з урахуванням рельєфу місцевості; алгоритм розрахунку кількості стрільб ЗРК до рубежів виконання бойових завдань; алгоритм оцінки показників ефективності застосування міжвидових (різнорідних) сил і засобів ППО ОК; алгоритм знаходження найкоротшого маршруту при русі по автошляхам.

При моделюванні відбиття одного повітряного удару по об'єктах (військах) маємо наступні показники (виміри):

a) $\mathrm{N}_{\mathrm{BA}_{\mathrm{j}, \mathrm{i}}}, \quad \mathrm{i}=\overline{1, \mathrm{n}_{\mathrm{BA}}}-$ кількість перехватів, що здійснив і-тий винищувач при j-ій реалізації процесу відбиття повітряного удару; $\mathrm{n}_{\mathrm{BA}}-$ кількість винищувачів, що задіяні в прикритті об’єктів (військ) при відбитті повітряного удару;

б) $\mathrm{N}_{3 \mathrm{~PB}_{\mathrm{j}, \mathrm{i}}}, \mathrm{i}=\overline{1, \mathrm{n}_{\text {зРв }}}-$ кількість стрільб, що здійснив i-тий зенітний ракетний підрозділ (вогнева одиниця) при ј-тій реалізації процесу відбиття повітряного удару; $\mathrm{n}_{\text {зрв }}$ - кількість зенітних ракетних підрозділів (вогневих одиниць), що задіяні в прикритті об'єктів (військ) при відбитті повітряного удару;

в) $\mathrm{N}_{\text {ппо св } \mathrm{j,i}}, \quad \mathrm{i}=\overline{1, \mathrm{n}_{\text {Ппо св }}}-$ кількість стрільб, що здійснив і-тий підрозділ (вогнева одиниця) ППО СВ при ј-тій реалізації процесу відбиття повітряного удару; $\mathrm{n}_{\text {Ппо св }}$ - кількість підрозділів (вогневих одиниць) ППО СВ, що задіяні в прикритті об'єктів (військ) при відбитті повітряного удару; 
г) $\mathrm{Q}_{\mathrm{BA}}, \mathrm{i}=\overline{1, \mathrm{n}_{\mathrm{BA}}}-$ кількість знищених ЗПН і-тим винищувачем при j-тій реалізації процесу відбиття повітряного удару;

д) $\mathrm{Q}_{3 \mathrm{~PB}_{\mathrm{j}, \mathrm{i}}}, \quad \mathrm{i}=\overline{1, \mathrm{n}_{\text {зРв }}}-$ кількість знищених ЗПН і-тим зенітним ракетним підрозділом (вогневою одиницею) при ј-тій реалізації процесу відбиття повітряного удару;

е) $\mathrm{Q}_{\text {ппо } \mathrm{CB}_{\mathrm{j}, \mathrm{i}}}, \mathrm{i}=\overline{1, \mathrm{n}_{\text {ппо св }}}-$ кількість знищених ЗПН і-тим підрозділом (вогневою одиницею) ППО СВ при ј-тій реалізації процесу відбиття повітряного удару;

ж) $\mathrm{U}_{\mathrm{BA}_{\mathrm{j}, \mathrm{i}}}, \quad \mathrm{i}=\overline{1, \mathrm{n}_{\mathrm{BA}}}-$ ознака знищення i-го винищувача при j-тій реалізації процесу відбиття повітряного удару;

и) $\mathrm{U}_{3 \mathrm{~PB}_{\mathrm{j}, \mathrm{i}}}, \mathrm{i}=\overline{1, \mathrm{n}_{3 \mathrm{~PB}}}-$ ознака знищення $\mathrm{i}$-го зенітного ракетного підрозділу (вогневої одиниці) при ј-ій реалізації процесу відбиття повітряного удару;

к) $\mathrm{U}_{\text {ппо } \mathrm{CB}_{\mathrm{j}, \mathrm{i}}}, \quad \mathrm{i}=\overline{1, \mathrm{n}_{\text {Ппо св }}}-$ ознака знищення i-го підрозділу (вогневої одиниці) ППО СВ при ј-тій реалізації процесу відбиття повітряного удару;

л) $\mathrm{U}_{\mathrm{PTB}_{\mathrm{j}, \mathrm{i}}}, \quad \mathrm{i}=\overline{1, \mathrm{n}_{\mathrm{PTB}}}-$ ознака знищення i-го засобу РТВ при $\mathrm{j}$-ій реалізації процесу відбиття повітряного удару; $\mathrm{n}_{\text {Ртв }}$ - кількість засобів РТВ, що задіяні в наданні РЛІ для прикриття об’єкту (військ) при відбитті повітряного удару;

м) $\mathrm{U}_{\Pi \text { Пн }}, \mathrm{i}=\overline{1, \mathrm{n}_{\text {ПнА }}}-$ ознака знищення $\mathrm{i}$-го пункту наведення авіації (ПНА) при ј-тій реалізації процесу відбиття повітряного удару; $\mathrm{n}_{\text {пнА }}-$ кількість ПНА, що задіяні в наданні винищувачів на ЗПН для вирішення завдання прикриття об’єкту (військ) при відбитті повітряного удару;

н) $\mathrm{U}_{\text {Кп ок }}$ - ознака знищення пункту управління (ПУ) авіації та ППО командного пункту (КП) оперативного командування (ОК), при ј-тій реалізації процесу відбиття повітряного удару; 
п) $\mathrm{U}_{\mathrm{OБ}_{\mathrm{j}, \mathrm{i}}}, \quad \mathrm{i}=\overline{1, \mathrm{n}_{\mathrm{OБ}}}-$ ознака нанесення удару по i-му об’ єкту (військам), що прикривається, при ј-ій реалізації процесу відбиття повітряного удару.

Ознаки ж)-н) можуть приймати два значення $\mathrm{U}_{\mathrm{j}, \mathrm{i}}=0$ - i-тий засіб не знищений, $\mathrm{U}_{\mathrm{j}, \mathrm{i}}=1$ - i-тий засіб знищений при j-тій реалізації процесу відбиття повітряного удару. Ознака о) може приймати два значення $\mathrm{U}_{\mathrm{Ob}_{\mathrm{j}, \mathrm{i}}}=0$ - удар по iму об'єкту (військам) не нанесено, $\mathrm{U}_{\mathrm{OБ}_{\mathrm{j}, \mathrm{i}}}=1$ - нанесено удар по і-му об'єкту (військам) при ј-ій реалізації процесу відбиття повітряного удару.

Загальна кількість перехватів, здійснених силами та засобами ВА при j-ій реалізації процесу відбиття повітряного удару по об'єктах (військах) визначається наступним чином:

$$
\mathrm{N}_{\mathrm{BA}_{\mathrm{j}}}=\sum_{\mathrm{i}=1}^{\mathrm{n}_{\mathrm{BA}}} \mathrm{N}_{\mathrm{BA}_{\mathrm{j}, \mathrm{i}}}
$$

Загальна кількість стрільб, здійснених силами та засобами ЗРВ при ј-тій реалізації процесу відбиття повітряного удару по об'єктах (військах) визначається наступним чином:

$$
\mathrm{N}_{3 \mathrm{~PB}_{\mathrm{j}}}=\sum_{\mathrm{i}=1}^{\mathrm{n}_{3 P B}} \mathrm{~N}_{3 \mathrm{~PB}_{\mathrm{j}, \mathrm{i}}}
$$

Загальна кількість стрільб, здійснених силами та засобами ППО СВ при јтій реалізації процесу відбиття повітряного удару по об’єктах (військах) визначається наступним чином:

$$
\mathrm{N}_{\text {ППО Св }}=\sum_{\mathrm{i}=1}^{\mathrm{n}_{\text {Ппо CB }}} \mathrm{N}_{\Pi \Pi О \mathrm{CB}_{\mathrm{j}, \mathrm{i}}} \cdot
$$

Загальна кількість впливів по ЗПН за підрозділи ВА, ЗРВ, ППО СВ при јій реалізації процесу відбиття повітряного удару по об'єктах (військах) визначається наступним чином:

$$
\mathrm{N}_{\Sigma_{\mathrm{j}}}=\mathrm{N}_{\mathrm{BA}_{\mathrm{j}}}+\mathrm{N}_{3 \mathrm{~PB}_{\mathrm{j}}}+\mathrm{N}_{\Pi \Pi \mathrm{\Pi \Pi} \mathrm{CB}_{\mathrm{j}}} \cdot
$$

Оцінка загальної кількості впливів по ЗПН за підрозділи ВА, ЗРВ, ППО СВ 
визначається як середнє арифметичне:

$$
\mathrm{N}_{\Sigma}=\frac{1}{\mathrm{~m}} \sum_{\mathrm{j}=1}^{\mathrm{m}} \mathrm{N}_{\Sigma_{\mathrm{j}}},
$$

де $\mathrm{m}$ - кількість реалізацій процесу відбиття повітряного удару по об'єктах (військах).

Загальна кількість знищених ЗПН силами та засобами ВА при ј-тій реалізації процесу відбиття повітряного удару по об’єктах (військах) визначається наступним чином:

$$
\mathrm{Q}_{\mathrm{BA}_{\mathrm{j}}}=\sum_{\mathrm{i}=1}^{\mathrm{n}_{\mathrm{BA}}} \mathrm{Q}_{\mathrm{BA}_{\mathrm{j}, \mathrm{i}}} .
$$

Загальна кількість знищених ЗПН силами та засобами ЗРВ при ј-ій реалізації процесу відбиття повітряного удару по об’єктах (військах) визначається наступним чином:

$$
\mathrm{Q}_{3 \mathrm{~PB}_{\mathrm{j}}}=\sum_{\mathrm{i}=1}^{\mathrm{n}_{3 \mathrm{~PB}}} \mathrm{Q}_{3 \mathrm{~PB}_{\mathrm{j}, \mathrm{i}}} \cdot
$$

Загальна кількість знищених ЗПН силами та засобами ППО СВ при ј-тій реалізації процесу відбиття повітряного удару по об’єктах (військах) визначається наступним чином:

$$
\mathrm{Q}_{\Pi \Pi о \mathrm{CB}_{\mathrm{j}}}=\sum_{\mathrm{i}=1}^{\mathrm{n}_{\text {пाо } \mathrm{CB}}} \mathrm{Q}_{\Pi \Pi о \mathrm{CB}_{\mathrm{j}, \mathrm{i}}}
$$

Загальна кількість знищених ЗПН підрозділами ВА, ЗРВ, ППО СВ при ј-ій реалізації процесу відбиття повітряного удару по об’єктах (військах) визначається наступним чином:

$$
\mathrm{Q}_{\Sigma_{\mathrm{j}}}=\mathrm{Q}_{\mathrm{BA}_{\mathrm{j}}}+\mathrm{Q}_{3 \mathrm{~PB}_{\mathrm{j}}}+\mathrm{Q}_{\Pi \Pi о \mathrm{CB}_{\mathrm{j}}}
$$

Оцінка математичного очікування кількості знищених ЗПН підрозділами ВА, ЗРВ, ППО СВ визначається як середнє арифметичне:

$$
\mathrm{M}_{\mathrm{L \Sigma}}=\frac{1}{\mathrm{~m}} \sum_{\mathrm{j}=1}^{\mathrm{m}} \mathrm{Q}_{\Sigma_{\mathrm{j}}} .
$$


Загальна кількість знищених винищувачів при ј-ій реалізації процесу відбиття повітряного удару по об’єктах (військах) визначається наступним чином:

$$
\mathrm{U}_{\mathrm{BA}_{\mathrm{j}}}=\sum_{\mathrm{i}=1}^{\mathrm{n}_{\mathrm{BA}}} \mathrm{U}_{\mathrm{BA}_{\mathrm{j}, \mathrm{i}}}
$$

Загальна кількість знищених зенітних ракетних підрозділів при ј-ій реалізації процесу відбиття повітряного удару по об’єктах (військах) визначається:

$$
\mathrm{U}_{3 \mathrm{~PB}_{\mathrm{j}}}=\sum_{\mathrm{i}=1}^{\mathrm{n}_{3 P B}} \mathrm{U}_{3 \mathrm{~PB}_{\mathrm{j}, \mathrm{i}}}
$$

Загальна кількість знищених підрозділів ППО СВ при ј-ій реалізації процесу відбиття повітряного удару по об’єктах (військах) визначається наступним чином:

$$
\mathrm{U}_{\Pi \Pi О \mathrm{CB}_{\mathrm{j}}}=\sum_{\mathrm{i}=1}^{\mathrm{n}_{\Pi \Pi о} \mathrm{cB}} \mathrm{U}_{\Pi \Pi О \mathrm{CB}_{\mathrm{j}, \mathrm{i}}} .
$$

Загальна кількість знищених засобів РТВ при ј-ій реалізації процесу відбиття повітряного удару по об'єктах (військах) визначається наступним чином:

$$
\mathrm{U}_{\mathrm{PTB}_{\mathrm{j}}}=\sum_{\mathrm{i}=1}^{\mathrm{n}_{\mathrm{PTB}}} \mathrm{U}_{\mathrm{PTB}_{\mathrm{j}, \mathrm{i}}}
$$

Загальна кількість знищених ПНА при ј-ій реалізації процесу відбиття повітряного удару по об'єктах (військах) визначається наступним чином:

$$
\mathrm{U}_{\Pi H \mathrm{~A}_{\mathrm{j}}}=\sum_{\mathrm{i}=1}^{\mathrm{n}_{\Pi \mathrm{H}}} \mathrm{U}_{\Pi H \mathrm{j}_{\mathrm{j}, \mathrm{i}}} .
$$

Загальна кількість знищених своїх засобів ВА, ЗРВ, ППО СВ, РТВ, ПУ авіації та ППО КП ОК при ј-тій реалізації процесу відбиття повітряного удару по об'єктах (військах) визначається наступним чином:

$$
\mathrm{U}_{\Sigma_{\mathrm{j}}}=\mathrm{U}_{\mathrm{BA}_{\mathrm{j}}}+\mathrm{U}_{3 \mathrm{~PB}_{\mathrm{j}}}+\mathrm{U}_{\Pi \Pi О \mathrm{CB}_{\mathrm{j}}}+\mathrm{U}_{\mathrm{PTB}_{\mathrm{j}}}+\mathrm{U}_{\Pi \mathrm{\Pi H}_{\mathrm{j}}}+\mathrm{U}_{\text {КП ОК }} \cdot
$$


Оцінка математичного очікування кількості знищених своїх засобів ВА, ЗРВ, ППО СВ, РТВ, ПУ авіації та ППО КП ОК визначається як середнє арифметичне:

$$
\mathrm{M}_{\Pi \Sigma}=\frac{1}{\mathrm{~m}} \sum_{\mathrm{j}=1}^{\mathrm{m}} \mathrm{U}_{\Sigma_{\mathrm{j}}}
$$

Оцінка імовірності прикриття і-го об’ єкту (військ) визначається як:

$$
\mathrm{P}_{\mathrm{Ob}_{\mathrm{i}}}=1-\frac{1}{\mathrm{~m}} \sum_{\mathrm{j}=1}^{\mathrm{m}} \mathrm{U}_{\mathrm{Ob}_{\mathrm{j}, \mathrm{i}}} \text {. }
$$

Оскільки оцінки показників ефективності (5), (10), (17), (18) отримуються статистичними методами, то їх точність і достовірність залежать від кількості m реалізацій процесу відбиття повітряного удару по об'єктах (військах).

Таким чином, якщо задана точність і достовірність, які повинні бути досягнені при оцінці показників ефективності, то необхідна для цього кількість m реалізацій процесу відбиття повітряного удару по об’єктах (військах) може бути знайдена як мінімальна кількість (але не менше 10), при якій виконується комплексна умова:

$$
\left\{\begin{array}{l}
\mathrm{m} \geq 10 ; \\
\Phi\left(\frac{\Delta \mathrm{N}}{\sqrt{\frac{\mathrm{D}_{\mathrm{N}}}{\mathrm{m}}}}\right) \leq \frac{\gamma}{2} \cap \Phi\left(\frac{\Delta \mathrm{M}_{\amalg}}{\sqrt{\frac{\mathrm{D}_{\mathrm{M}_{\amalg}}}{\mathrm{m}}}}\right) \leq \frac{\gamma}{2} \cap \Phi\left(\frac{\Delta \mathrm{M}_{\Pi}}{\sqrt{\frac{\mathrm{D}_{\mathrm{M}_{\Pi}}}{\mathrm{m}}}}\right) \leq \frac{\gamma}{2},
\end{array}\right.
$$

де $\Phi(\bullet)$ - функція Лапласа; $\Delta \mathrm{N}, \Delta \mathrm{M}_{ц}, \Delta \mathrm{M}_{\Pi}$ - задана точність оцінок відповідних показників; $\mathrm{D}_{\mathrm{N}} \neq 0, \mathrm{D}_{\mathrm{M}_{\Perp}} \neq 0, \mathrm{D}_{\mathrm{M}_{\Pi}} \neq 0$ - дисперсії оцінок відповідних показників; $\gamma$ - задана достовірність оцінок показників.

Дисперсії оцінок $\mathrm{D}_{\mathrm{N}}, \mathrm{D}_{\mathrm{M}_{ц}}, \mathrm{D}_{\mathrm{M}_{\Pi}}$ відповідних показників визначаються наступним чином: 


$$
\left\{\begin{array}{l}
\mathrm{D}_{\mathrm{N}}=\frac{1}{\mathrm{~m}-1} \sum_{\mathrm{j}=1}^{\mathrm{m}}\left(\left(\mathrm{N}_{\Sigma_{\mathrm{j}}}-\mathrm{N}_{\Sigma}\right)^{2}\right), \\
\mathrm{D}_{\mathrm{M}_{\mathrm{LL}}}=\frac{1}{\mathrm{~m}-1} \sum_{\mathrm{j}=1}^{\mathrm{m}}\left(\left(\mathrm{Q}_{\Sigma_{\mathrm{j}}}-\mathrm{M}_{\mathrm{L \Sigma}}\right)^{2}\right), \\
\mathrm{D}_{\mathrm{M}_{\Pi}}=\frac{1}{\mathrm{~m}-1} \sum_{\mathrm{j}=1}^{\mathrm{m}}\left(\left(\mathrm{U}_{\Sigma_{\mathrm{j}}}-\mathrm{M}_{\Pi \Sigma}\right)^{2}\right),
\end{array}\right.
$$

На мінімальну кількість реалізацій процесу відбиття повітряного удару по об’єктах (військах) т також впливає умова:

$$
\left\{\begin{array}{l}
\mathrm{D}_{\mathrm{N}} \neq 0 ; \\
\mathrm{D}_{\mathrm{M}_{\mathrm{L}}} \neq 0 ; \\
\mathrm{D}_{\mathrm{M}_{\Pi}} \neq 0,
\end{array}\right.
$$

оскільки дисперсії оцінок відповідних показників містяться в знаменниках (19).

Тобто при проведенні моделювання відбиття повітряних ударів по об’єктах (військах) необхідно збільшувати кількість реалізацій т до тих пір (не менше 10) поки не буде виконана умова (21), а потім перевіряти виконання умови (19).

Інформаційно-розрахункова система "АРГУМЕНТ 2021" використовується в штабах Повітряних Сил, штабі зенітної ракетної бригади (полку), командному пункти зенітного ракетного дивізіону для підтримки прийняття рішення на бойові дії, а також є інтерактивною і часових обмежень на іiї роботу не існує. 